\title{
Smart College Bus Management System
}

\author{
R.Karthiban, S. M. Aaruthraa Raajapathi, B. Hemalatha, M. kouselya, Padmapriya Alagappan
}

\begin{abstract}
that supports current challenges and issues that's crucial .Monitoring includes the tracking of one who is moving into the bus, the time of moving into the bus and also the place wherever he's boarded into the bus provided for student bus management system. This whole system consists of frequency Identification (RFID), Fingerprint detector, Wi-Fi and also the Microcontroller. The system consists of 2 main modules In-bus module and Base station module. Once the person is on the brink of get in to the bus, he has got to swipe the RFID card, the RFID tag is scanned by the RFID reader within the In-bus module and also the tag range is then sent to BASE-station via GSM. The signals from ATMEGA328 microcontroller, USB-TTL Convertor's send acceptable RFID tag range to the storage. The microcontroller searches for the received tag range at the bottom station and links the connected tag range information. Associated data entries are created and saved in the new database for each individual entries. This module then stores the info within the MYSQL. Real time analysis is also the part of this work. Once when the data is received reports are generated and is sent to the appropriate authorities.
\end{abstract}

Keywords: RFID reader, Fingerprint sensor, Wi-Fi, Microcontroller.

\section{INTRODUCTION}

Our project consists of powerful microcontroller, input section that consists of the sensing devices and output section that gives the final residue of the sensed data. The input section consists of Fingerprint detector, Wi-Fi and therefore the Microcontroller which will be employed for the sensing operations. The output section consists of data storage with proper data stored in appropriate fields based on each new entry. RFID may be a frequency Identification technology that has been employed in several fields together with solid waste management, human, animal, merchandise and object pursuit and therefore the many researches evidenced that the implementation and supervising the RFID is incredibly simple and it will increase the potency of the system at an occasional price. Associate degree automatic system may be a one that doesn't want any external directions by people in general rather than it acts per the case mechanically.

Revised Manuscript Received on April 18, 2020.

* Correspondence Author

Mr.R.Karthiban, Assistant Professor

S. M. Aaruthraa Raajapathi*, UG Students,Department of Computer Science and Engineering, Sri Shakthi Institute of Engineering and Technology, Coimbatore

B. Hemalatha, UG Students,Department of Computer Science and Engineering, Sri Shakthi Institute of Engineering and Technology, Coimbatore

M. kouselya, UG Students,Department of Computer Science and Engineering, Sri Shakthi Institute of Engineering and Technology, Coimbatore

Padmapriya Alagappan, UG Students,Department of Computer Science and Engineering, Sri Shakthi Institute of Engineering and Technology, Coimbatore.

(C) The Authors. Published by Blue Eyes Intelligence Engineering and Sciences Publication (BEIESP). This is an open access article under the CC BY-NC-ND license (http://creativecommons.org/licenses/by-nc-nd/4.0/)
A frequency Identification Reader (RFID reader) may be a device that is employed to gather the knowledge from associate degree RFID tag, by sensing Radio waves. RFID may be a technology just like barcodes and somewhat extent thereto. RFID has additional benefits in comparison to barcodes. RFID reader identifies the tags at intervals that vary of three to three hundred feet. This technology scans the objects terribly quickly and allows the actual product to get scanned, even once it's enclosed by many alternative objects ATMEGA328/P may be a low power CMOS 8-bit Microcontroller that stands in support to the AVR that increased computer architecture. By death penalty powerful directions in an exceedingly single clock cycle, the ATMEGA328/p achieves outturn near to1MIPS per megacycle per second.

\section{LITERATURE SURVEY}

\section{[1] Digital bus pass checking using QR-Code}

This project provides a good resolution for managing bus pass information. Their system has 3 logins that is for user, admin and conductor. This method provides internet application in addition to robot application for individuals to induce their Bus passes on-line. This method is helpful for users to induce their bus pass on-line rather than standing in long queues to get their bus passes. This method is useful to scale back the paper work, time consumption and the user gets the bus pass in straightforward and quicker manner. User will refill their account and extend the validity of card once the pass goes to expire. This method provides practicality like accessing basic info of user for authentication and supply Bus pass for the user while not putting them in long queues. This method provides security possibility for user. The conductor in bus would be able to verify the locomote scanning the QR code provided on the pass with a counseled device. The notification generated by the system would be send to the user in type of message like once wherever and what time the cardboard was use. This method additionally provides on-line payment facilities that saves time and energy.

Index Terms-Android Mobile, on-line Payment, consumer server, QR Code, Privacy and Authentication.

[2] Advanced college bus management with the help of ASP.NET and CSHARP

The here within proposed Bus Management software system Project may be a desktop system geared toward students, school administration to take care of bus facility. The system takes student info as Associate in monitoring input supply and tries to take care of bus services. It permits flexibility throughout these processes.

\section{Published By:}

Blue Eyes Intelligence Engineering \& Sciences Publication DOI: 10.35940/ijeat.D8658.049420

Journal Website: www.ijeat.org 


\section{Smart College Bus Management System}

The system generates complete reports associated with the Bus Management i.e. Fees paid, dues, rout no. \& bus stop. The reports highlight varied bus services and options of the bus, which might be subjected to enhancements particularly for the faculty administration to improve the bus transport system. The system needs a relatively touch of resources like memory, input/output devices, and space. The system overall keep approach in highlight key options of the bus services. [3] Smart College Bus Tracking Management System And Its Application

The bus pursuit system may be a value effective and economical system. In addition to other methods proposed this method includes four application that are going to be developed. 1st application is establishing communication between school server and bus system that is capable of providing period information relating to the present location of buses. Second application is causation a gaggle messages i.e. alert messages to the students waiting at consequent stop, changes in current route, bus number, etc., thus it saves the time of awaiting students for their buses. Third application is generation of e- bus pass system that is Associate in monitoring ecofriendly as there's no necessity for the generation of plastic bus passes. Last application is developing Associate in monitoring emergency handling system which can send alert messages at the same time to varsity, police and motorcar surveillances just in case of accidents

\section{OBJECTIVE}

\section{A. Easy To Use}

The main objective of our project is to develop a platform that is easy and very simple to use. The user does not require complex knowledge to handle it. All that the user has to do is swipe his/her tag on the RFID reader and has to imprint his/her fingerprint impression for the authentication purpose on the fingerprint sensor. Only after proper verified authentication entries are made in the database. This not only saves time and money but also saves human energy. In our model we have LED indicators which works after authentication. The blinking of light indicates the student's fee status and boarding location status.

\section{B. No Human Intervention Required}

The platform which we have developed requires no monitoring as immediate data streaming is sent to the supervisor as SMS and students who have availed bus without fees payment and those who have boarded in different location from his/her allotted location is also pointed out. Hence no monitoring is required and later fine can be imposed on those students who have violated college norms of transportation.

\section{Real Time Analysis}

Our project's main advantage is that we get the data insights immediately after the tag is swiped on the RFID reader. We don't have to wait until all the students to board the bus and for the bus to reach college and then wait for the admin to filter the data collected and then pick up the students rather immediately the staff in charge could ask the student to get off the bus immediately. Our project is based on the continuous analytics as it delivers results as soon as the event happens. Only the data

Journal Website: www.ijeat.org of those students who haven't paid his/her fees and those who have boarded in different location would be streamed.

\section{Less Security Breach}

Security is high on RFID Based Bus Management when compared with our traditional paper based management. We have two step verification in our model to make sure that the student does not carry other's tag to cheat on. To identify this cheat Biometrics is used which provides higher security, fingerprint verification is made immediately after the student swipes the tag, if he/she fails to imprint his/her fingerprint impression this is also taken into account to the database. Fingerprint is also one of the technologies to find criminology. The process involves placing the finger to verify his/her impression on the reader and later get scanned. The pattern of the fingerprint so obtained is compared with the already saved pattern to find its match. Recognition of the fingerprint pattern takes half a second so it does not take much time.

\section{PROPOSED SYSTEM}

The whole system consists of two parts, inputs and outputs. In the proposed work. Input is composed of fingerprint sensor, wireless Internet connection and the microcontroller. The output portion is the data storage, i.e. the database. The input module is set in the bus, where we would like to know where the person enters the bus, the time and the name of the bus user. A card of identity is issued for anyone who is supposed to belong to that bus, which contains the person's details. At the point when the student is going to get in to the bus, he needs to swipe the personality card attached with the unique RFID code and needs to get into the , when the individual swipes the character card and for verification his unique mark additionally is ought to be kept, the RFID per user peruses the character card and sends the label number of that RFID tag to the microcontroller, the microcontroller in the in-transport module checks whether that specific individual is has been registered with that specific transport or not. On the off chance if that individual has not been registered with that specific transport, the microcontroller sends the label number of that character card to the database, and the boarding place of the student. The complete data that is spot, time and label number of the individual is transmitted to database and later on an alert message with these information has been transmitted immediately to an authority who has taken incharge of monitoring student's transportation details .LED indicators are also attached along with the kit, when green lits it indicates that the student has paid hid fees and has boarded in his allotted location. The red indicates that the student has availed bus facilities without the payment of bus fee. The orange indicates that the student has paid his fees but has boarded in a different boarding location. The LED lights blinks only after right authentication this information is also stored in the database.
Published By:

Blue Eyes Intelligence Engineering \& Sciences Publication 


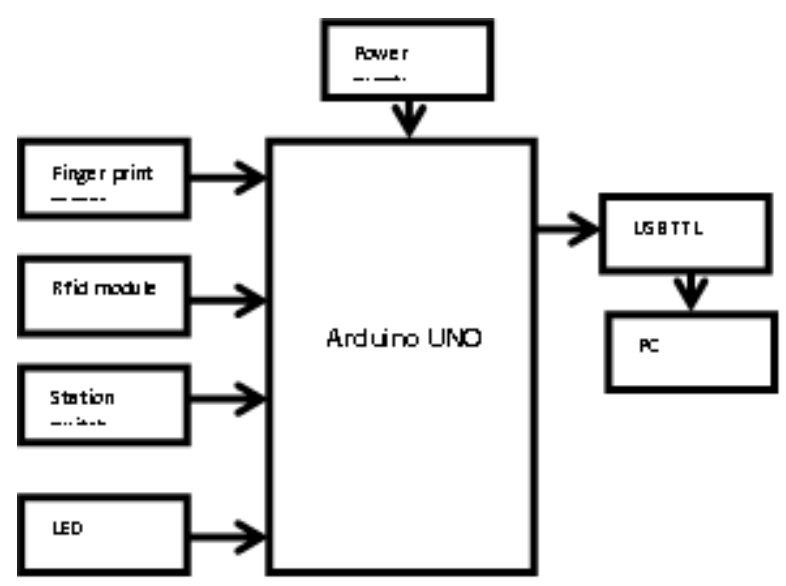

Fig.1. Block Diagram Of The Device

\section{METHODOLOGY}

The steps that are followed

i. Registration Phase

ii. Communication between Tag and Reader

iii. Authentication

iv. Information Storage

v. Alert Message Streaming

\section{Registration Phase}

Each tag is uniquely encoded to identify each personality distinctively. The encoding is done using combination of digital serial numbers and alphabets(it is a 12 digit code) it is stored along with the students details including his name, fees, payment details, point of boarding and his/her biometric fingerprint pattern. All the details are stored in back end server.

\section{Communication between tag and reader}

As soon as the tag is sensed in the electromagnetic zone of the RFID reader, it decodes the data from the tag and then the information is forwarded to the personal computer for further more processing and filtering based on the inputs.

\section{Authentication}

For authentication purpose fingerprint is used after the student taps his tag on the reader he has to keep his finger on the fingerprint sensor for authentication purpose. The server extracts tag code and the tag holder information from the database and then calculation are done in the back end server. That is the comparison of already stored finger print pattern and the obtained fingerprint if matched it is simply stored as matched in fingerprint match column in the database else it is stored as unmatched.

\section{Information Storage}

All the information are stored in the database under column named as created at which includes date and time, Entry Id is the serial number, IdNo is the students Roll number, location includes students allotted point of boarding, Fees details comprises of the status of fees payment whether he/she has paid his/her fees or not, Authentication column includes the fingerprint pattern match or unmatched if the student fails to imprint his/her impression then that column would be blank.

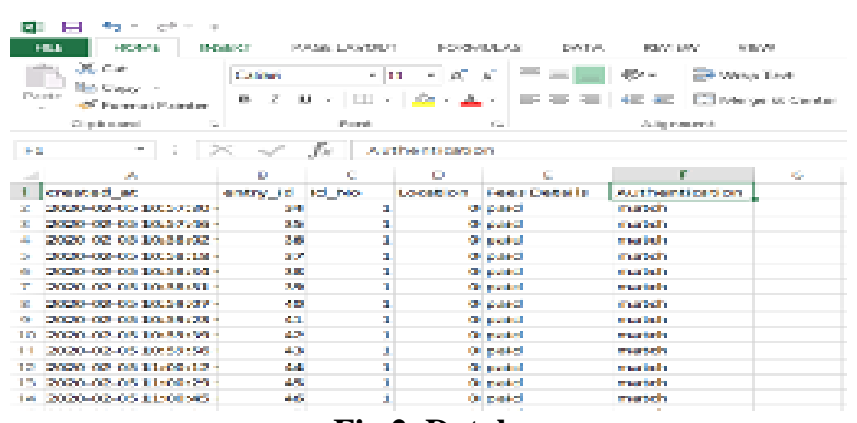

Fig.2. Database

\section{Alert Message Streaming}

Data streaming is done as alert SMS message to a supervisor who is in charge for those entries in the database that appears unpaid in the fees details column and when location does not match with the already registered location. This helps us to pick up the students on the go. Data from database with these constrained violated alone is picked up and sent as alert SMS.

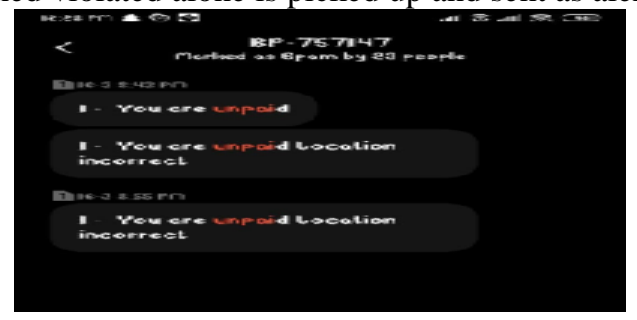

Fig.3.Alert Message

\section{TECHNOLOGY USED}

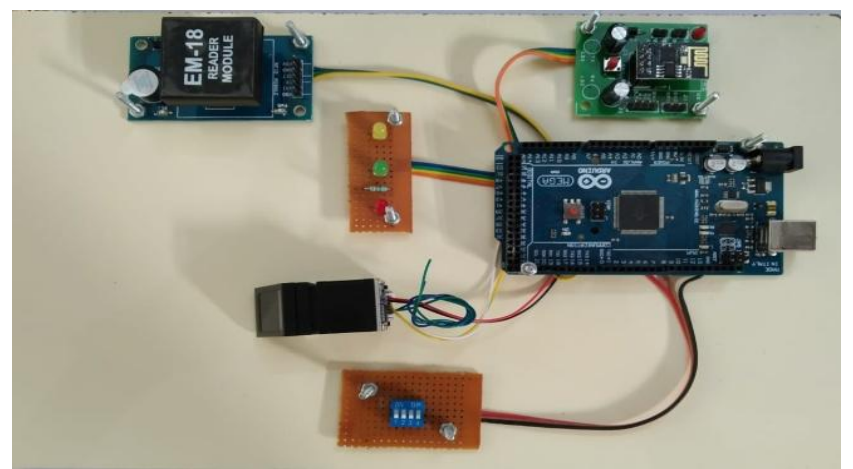

Fig.4. Final Setup Of The Device

\section{Arduino Ide}

Arduino IDE is an open source programming that is predominantly utilized for composing and arranging the code into the Arduino Module. It is legitimate Arduino programming, making code aggregation too simple that even a typical individual with no earlier specialized information can consider going all in with the learning procedure.

Published By:

Blue Eyes Intelligence Engineering \& Sciences Publication 


\section{Smart College Bus Management System}

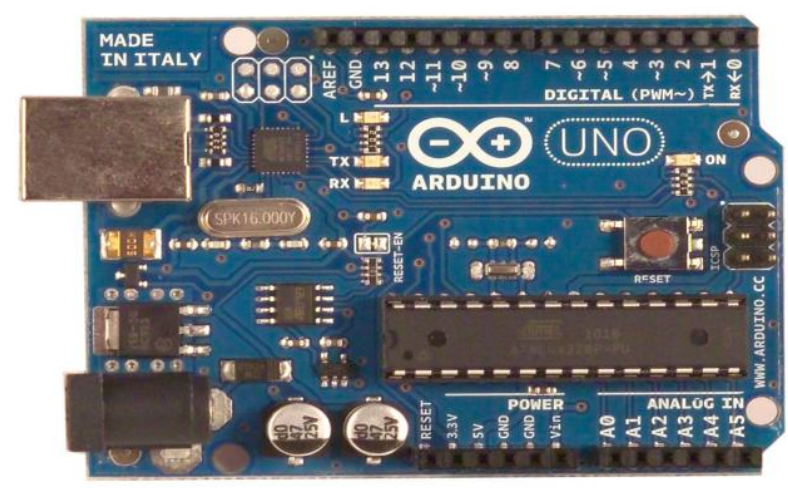

Fig.5. Arduino Uno

\section{Thing Speak}

An IOT stage that lets us store every one of our information in the cloud and create web of things applications. It provides instant visualization of the data posted by our device. The data is sent to this platform through our Arduino. Being it an open source IOT application and an API it is utilized to store and recover data which uses HTTP and MQTT show over the web or by methods for Local Area Network.

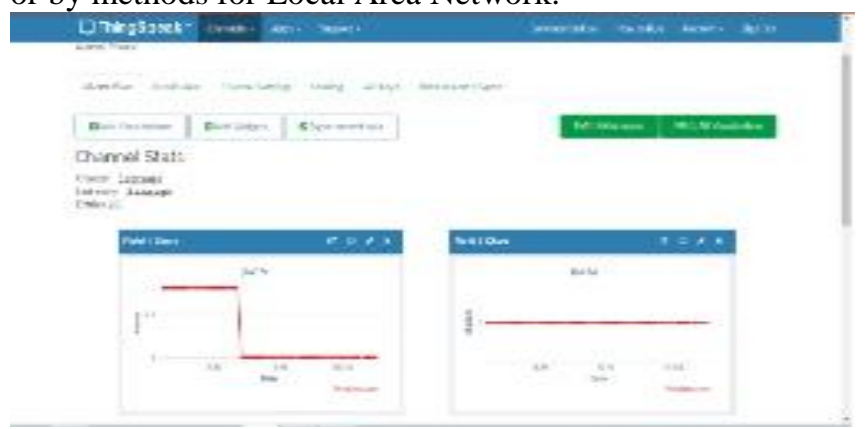

Fig.6. Data Visualization In Thingspeak

\section{Rfid Reader}

Automatically reads Rfid tags when swiped on it, it gathers unique information from the digitally encoded tag which is used to track individual tags. When the tag is scanned the antenna within the RFID tags picks up the radio waves and sends responses back to the reader.

\section{Rfid Tags}

Contains digitally encoded and electronically stored information uniquely about an individual or an item or something which has to be tracked or monitored.

\section{Finger Print Sensor}

Used for authentication purpose. There are chances for fraudulent in the cards and assaults hence to minimize those mishappenings finger print is checked so that no one other than the card holder can make use of the tag if suppose unauthorized person have access towards the card ,the data of mismatch of finger print will be stored in the database.

\section{Wifi Module}

Both the WIFI empowered gadget and our WI router has a WIFI chip and radio that permits it to impart over the arrangement of conventions known as Wi-Fi. A Wi-Fi switch has the equipment important for the switch divide just as an
Ethernet switch just as Wi-Fi module. Wi-Fi module interfaces with the PC without remote equipment and makes an interpretation of signs from switch to the PC client to utilize web inside the scope of Wi-Fi hotspot.

\section{Led Indicators}

Functions that has been assigned for the led indicators are as followed: The colour green indicates that the student has paid his fees and has boarded in his allotted location. When the LED colour blinks red it indicates that the student has availed bus facilities without the payment of bus fee. The LED colour when blinks orange indicates that the student has paid his fees but has boarded in a different boarding location. The led lights blinks only after right authentication this information is also stored in the database.

\section{CONCLUSION}

The RFID tag provides a protected and strong strategy for holding students identification with correct boarding location and payment of fees status. Computerized entry with student details are stored which could be referred anytime. Authentication with the help of fingerprint provides secured bus system and to identify each individual uniquely.

The main objective of the proposed system is to reduce man power and time.

\section{RESULTS AND DISCUSSIONS}

Our studies and experiments with RFID reader and Arduino in our project falls short of memory, so therefore when we bring in use for an institution with larger strengths additional storage unit is a necessity. In line with studies finger print detector is cost efficient when compared with face recognition but obviously it falls down when comparison is made based on quickness in capturing information. Additionally in future we could adopt GPS MODULE and CAMERA MODULE in replacements of station switches and fingerprint detector but the reason why we dint opt these technologies in our paper is first considering the cost and second the need of raspberry pie kit to support the above mentioned alternatives. Our desire was to develop a product that replaces manual checking of bus passes in colleges in an efficient, simple and affordable manner. Similar pattern of results were obtained by many researches and what is outstanding in our project is that we have included immediate streaming of data as SMS to a particular in- charge. The data that are captured here are the student details (Register no, boarding point, status of fee payment), this is then used for further analysis. These details could be later tracked down and predictions could be made.

\section{REFERENCES}

1. Anuradha Vishwakarma, Agarja Jaiswal, Ashwini Neware, Shruthi Ghime, Antara Marathe, Reshmi Deshmukh " GPS and RFID Based Intelligent Bus Tracking and Management System ". International Research journal of Engineering and Technolgy,Vol. 03, Issue: 03, March-2016.

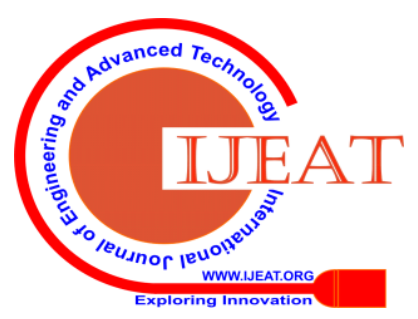


2. M.K. Khan, and J. Zhang, and X. Wang, Chaotic hash based fingerprint biometric remote user authentication scheme on mobile devices, Chaos Solitons and Fractals2008, vol.35(3),pp.519-524.

3. Komal Satish Agarwal, Kranthi Drive "RFID Based Intelligent Bus Management and Monitoring System". International Journal of Engineering \& Technology, ISSN: 2278-0181, Vol.3 Issue 7, July-2014.

4. H-Y.Chienand C-WHuang Alight weight RFID Protocol using substring Proceedings of International Federation for Information Processing, IFIP-2007, pp.422-431.

5. Li, Chun-Ta and Hwang, Min-Shiang An efficient biometrics-based remote user authentication scheme using smart cards, Journal of Network and Computer Applications-2010, vol.33(1), pp.1-5.

6. Y.-W. Lai, and S.-C. Chang, and C. Chang, An Improved Biometrics-based User Authentication Scheme without Concurrency System, International Journal of Intelligent Information Processing-2010,vol.1(1).

7. C. C. Lee and R. X. Chang and L. A. Chen Improvement of Li-Hwang's biometric-based remote user authentication scheme using smart cards, WSEAS Transactions on Communications-2011, vol.10(7),pp.193-200.

8. M.A. Hannan, A.M.Mustapha, A. Hussain, H.Basri "Intelligent Bus Monitoring and Management System”. World Congress on Engineering and Computer Science 2012 Vol II, October 24-26.

9. A. Das Analysis and improvement on an efficient biometric based remote user authentication scheme using smart cards, Information Security, IET-2011, vol.5(3), p.p.145-151.

10. Sunil Prannel narayan, Mansour H. Assaf, Shalvindra Krishneel Prasad “ Wireless Sensor Enabled public transportation System”. International Journal of Communications, Network and System Sciences, 2015,8,187-196.

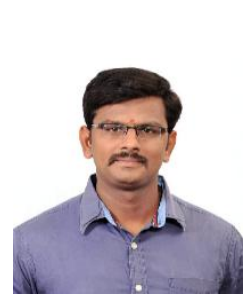

\section{AUTHORS PROFILE}

R.Karthiban, ASSISTANT PROFESSOR, Department of Computer Science and Engineering, Sri Shakthi institute of Engineering and

Technology, Coimbatore. rkarthiban@siet.ac.in

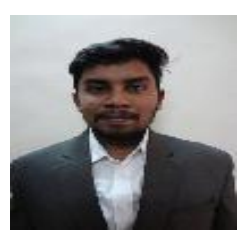

S.M. Aaruthraa Raajapathi UG Student, Department of Computer Science and Engineering, Sri Shakthi institute of Engineering and Technology, Coimbatore. aaruthraraajapthi1999@gmail.com

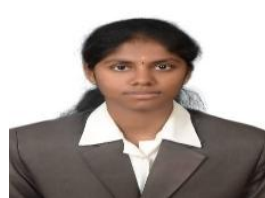

B. Hemalatha UG Student, Department of Computer Science and Engineering, Sri Shakthi institute of Engineering and Technology, Coimbatore. hemalathasubramaniyam4@gmail.com

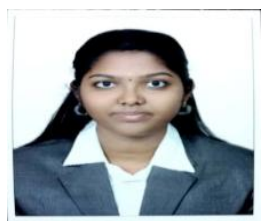

M. Kouselya UG Student, Department of Computer Science and Engineering,

Sri Shakthi institute of Engineering and

Technology,

Coimbatore.

kouselya2598@gmail.com

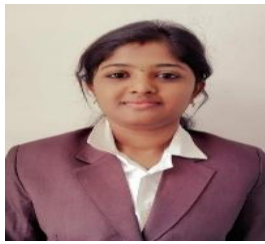

PadmapriyaAlagappan UG Student, Department of Computer Science and Engineering, Sri Shakthi institute of Engineering and Technology,

Coimbatore.padma98priya@gmail.com

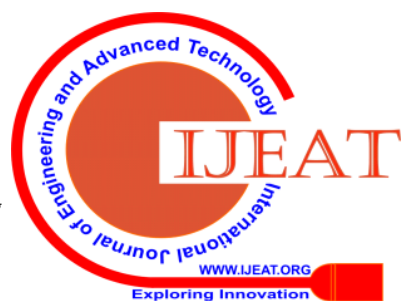

